Case Report

\title{
Bilateral Chylothorax as a Unique Presentation of Pancreaticobiliary or Upper Gastrointestinal Cancer
}

\author{
Nooraldin Merza $\left(\mathbb{D},{ }^{1}\right.$ John Lung $\mathbb{D}^{2},{ }^{2}$ Mazin Saadaldin, ${ }^{1}$ and Tarek Naguib ${ }^{1}$ \\ ${ }^{1}$ Department of Internal Medicine, Texas Tech University Health Sciences Center, Amarillo, TX, USA \\ ${ }^{2}$ School of Medicine, Texas Tech University Health Sciences Center, Amarillo, TX, USA \\ Correspondence should be addressed to Nooraldin Merza; nooraldin.merza@ttuhsc.edu
}

Received 24 April 2019; Accepted 17 June 2019; Published 2 July 2019

Academic Editor: Samer Al-Saad

Copyright ( 2019 Nooraldin Merza et al. This is an open access article distributed under the Creative Commons Attribution License, which permits unrestricted use, distribution, and reproduction in any medium, provided the original work is properly cited.

Chylothorax presents as exudate with lymphocytic predominance and high triglyceride-low LDH levels, usually due to a traumatic disruption of the thoracic duct, possibly iatrogenic. Other causes include malignancy, sarcoidosis, goiter, AIDS, or tuberculosis. Here we present a case of a 66-year-old male who came in with cough and shortness of breath for few weeks. A week earlier, at an ED visit, he was diagnosed with pneumonia based on CT angiogram of the chest without contrast that showed bilateral pleural effusion and bilateral pulmonary infiltrates. The CT-guided placement of bilateral chest tube drained $1160 \mathrm{cc}$ of creamy yellow fluid on the right and $1200 \mathrm{cc}$ of creamy yellow fluid on the left. CT chest/abdomen/pelvis showed bilateral ground-glass opacities within the lungs and possible bony metastasis. A whole-body bone scan showed multiple bony metastatic lesions throughout the skeleton. IR guided bone biopsy suggested upper GI or pancreaticobiliary cancer. Venous ultrasound with Doppler of left upper extremity showed findings suggestive of a nonocclusive DVT of proximal $/ \mathrm{mid}$ left subclavian vein which is difficult to compress. Eventually, malignancy-related DVT of the left subclavian/brachiocephalic vein was identified as the possible etiology for the bilateral chylothorax.

\section{Introduction}

Pleural effusion is suspected by dullness to percussion, confirmed by imaging, and worked up by thoracentesis [1]. Chylothorax, the finding of chyle in the pleural space, is diagnosed with pleural fluid triglycerides level greater than $110 \mathrm{mg} / \mathrm{dL}$, whereas less than $50 \mathrm{mg} / \mathrm{dL}$ excludes it [2]. Chylothorax presents as exudate with lymphocytic predominance with low LDH levels. However, other pleural fluid presentations with exudative or transudative nature and variable triglyceride, cholesterol, and LDH levels were reported in chylothorax [3]. Chylothorax develops most commonly due to a traumatic disruption of the thoracic duct, possibly iatrogenic. Other causes include malignancy, sarcoidosis, goiter, AIDS, and tuberculosis [4-6]. A retrospective review performed in a tertiary referral clinic suggested that surgery or trauma was the most common cause, with lymphoma or other malignancies accounting for only $16.7 \%$ of the cases [7]. Case reports in the literature have linked malignant causes of chylothorax to prostate carcinoma [8], gastric adenocarcinoma [9], mesothelioma [10], lymphomas [11-14], small cell lung cancer [15], and chronic lymphocytic leukemia [16]. The overall prognosis for solid tumor-associated chylothorax is poor, while prognosis is good for lymphoma-associated chylothorax if remission can be achieved [17]. We report a case of a patient presenting with bilateral chylothorax due to underlying pancreaticobiliary or upper gastrointestinal cancer.

\section{Case Presentation}

A 66-year-old male presented with few weeks of cough and shortness of breath. He had to lay on his side or prop himself up to breathe more comfortably at night. A week earlier, at an ED visit, he was diagnosed with pneumonia based on CT angiogram of the chest without contrast that showed bilateral pleural effusion and bilateral pulmonary infiltrates (Figure 1). Levofloxacin oral therapy was followed 


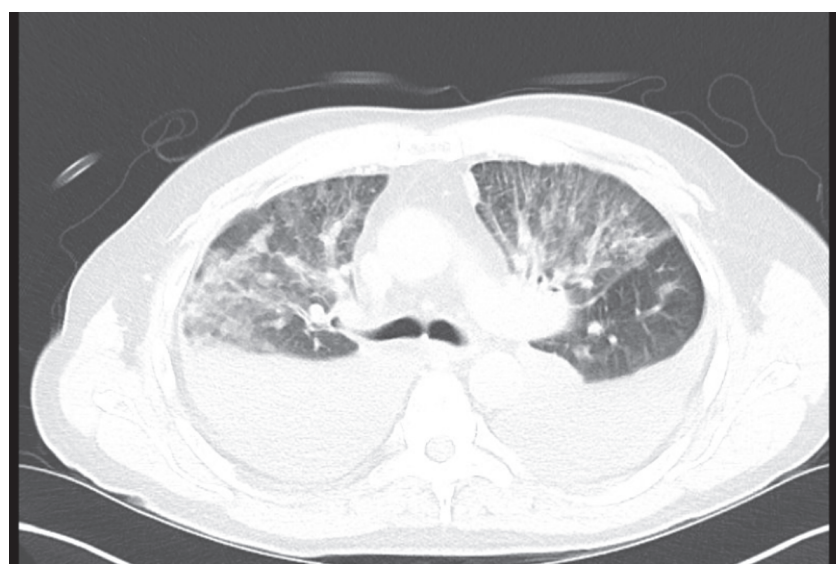

FIgURE 1: CT of the chest without contrast shows prominent parenchymal ground-glass changes. Large bilateral pleural effusions and moderate pericardial effusion.

by some improvement but he felt worse again. There is no significant past medical or trauma history other than right elbow trauma and right knee endoscopic surgery. He denied tobacco or drug use but endorsed occasional alcohol use. Lungs exam revealed only scant rales in the right lower lobe. He was afebrile, normotensive, and hypoxic with $\mathrm{SpO} 2$ of $91 \%$ on room air. Lab was only significant for elevated alkaline phosphatase 476, AST 46, and pro-BNP 147. EKG showed normal sinus rhythm. Ceftriaxone and azithromycin were started for pneumonia which failed outpatient therapy.

The CT-guided placement of bilateral chest tube drained $1160 \mathrm{cc}$ of creamy yellow fluid on the right and $1200 \mathrm{cc}$ of creamy yellow fluid on the left. Pleural fluid LDH was 226 units/L, triglycerides were $85 \mathrm{mg} / \mathrm{dL}$, total protein was 4.3 $\mathrm{gm} / \mathrm{dL}$, and cholesterol was $67 \mathrm{mg} / \mathrm{dL}$. Total serum protein was $7.8 \mathrm{gm} / \mathrm{dL}$. The fluid was diagnosed as exudative in nature (Light's criteria, pleural fluid protein/serum protein $>0.5$ ). The cytopathology evaluation of the pleural fluid was negative.

Antibiotics were stopped due to lack of growth in cultures. A few days after the right-sided chest tube was removed, a chest x-ray showed a recurrent right-sided pleural effusion.

Repeated CT thorax without contrast showed a moderate right-sided pleural effusion with right lower lobe atelectasis (Figure 2). A repeat left pleural fluid analysis showed triglycerides of $1066 \mathrm{mg} / \mathrm{dl}$, LDH of 363 units/L, total protein of $3.6 \mathrm{gm} / \mathrm{dL}$, and cholesterol of $53 \mathrm{mg} / \mathrm{dL}$, highly suggestive of chylothorax. A chest tube was placed again on the right side and octreotide and somatostatin were begun. Lymphocytic scintigraphy (Figure 3) showed no activity transmitted in the thoracic duct beyond the pelvis suggestive of a central obstruction. Numerous enlarged nodes were also seen in the inguinal and iliac areas, concerning for lymphoma.

CT Chest/abdomen/pelvis showed bilateral ground-glass opacities within the lungs and possible bony metastasis (Figure 4). A whole-body bone scan showed multiple bony metastatic lesions throughout the skeleton (Figure 5).

IR guided bone biopsy suggested upper GI or pancreaticobiliary cancer (patient's bone marrow biopsy showed

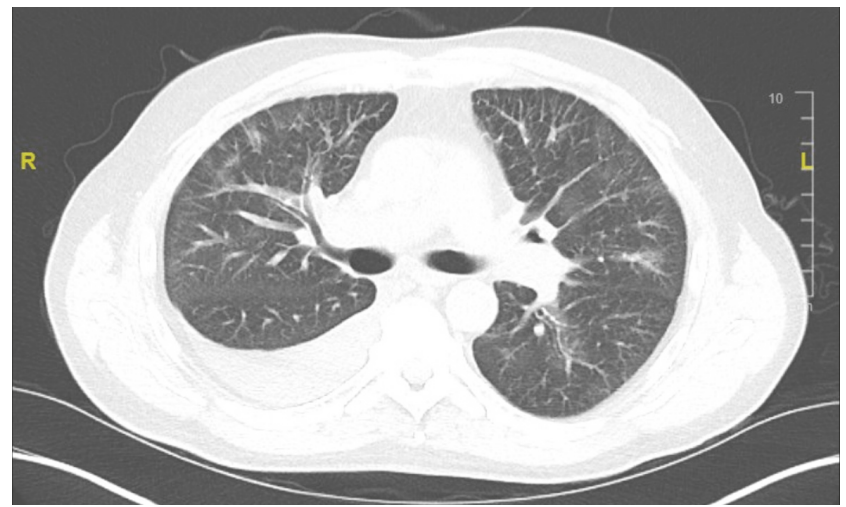

FIGURE 2: Repeat CT thorax without contrast showing moderatesized right pleural effusion with right lower lobe atelectasis.

poorly differentiated metastatic carcinoma cells but could not completely pinpoint to the site of origin but suggested pancreaticobiliary or upper gastrointestinal cancer). Other workups including peripheral blood flow cytometry, SPEP, IFE, and free light chain assay, TSH/free T4, serum quantiferon, ANA, CEA, and serum VEGF all were negative, while CA 199 was 402 units/mL.

We found that the patient had a deep vein thrombosis of the left subclavian/brachiocephalic vein, which most likely caused the bilateral chylothorax and was confirmed by CTA and upper extremity Doppler ultrasound (Figure 6).

Intravenous heparin was started, followed by Catheter Associated Thrombolysis (EKOS) of left subclavian vein. The heparin drip then switched to apixaban. After the patient's thrombolysis of brachial/subclavian left upper extremity vein was done, his chest tube output started to decrease. Leftsided chest tube was removed four days after the thrombolysis followed by right-sided chest tube seven days after the thrombolysis right before the patient was discharged for outpatient oncology care.

\section{Discussion}

High-volume chylothorax can present with nonspecific symptoms like upper respiratory infection. Rapid onset high volume chylothorax can present with dyspnea, hypovolemia, chest pain, and cough. Chylothorax is typically diagnosed in the context of pleural effusion with triglycerides content of more than $110 \mathrm{mg} / \mathrm{dL}$ diagnostic [3].

In our patient, the diagnosis was hampered by an inconclusive first sample from the chest tube. However, the pleural effusion was large enough where the chest tubes drained more than $1 \mathrm{~L}$ each of creamy yellow fluid. After recurrence, repeated analysis showed triglycerides greater than 1000 $\mathrm{mg} / \mathrm{dL}$, suggestive of a bilateral chylothorax. Eventually, malignancy-related DVT of the left subclavian/brachiocephalic vein was identified as the possible etiology for the bilateral chylothorax. A deep vein thrombosis of the left subclavian vein can lead to pressure in return of the thoracic duct, which can cause leakage into the pleural space [18]. The thoracic duct will drain into the left side of the neck $92-95 \%$ 

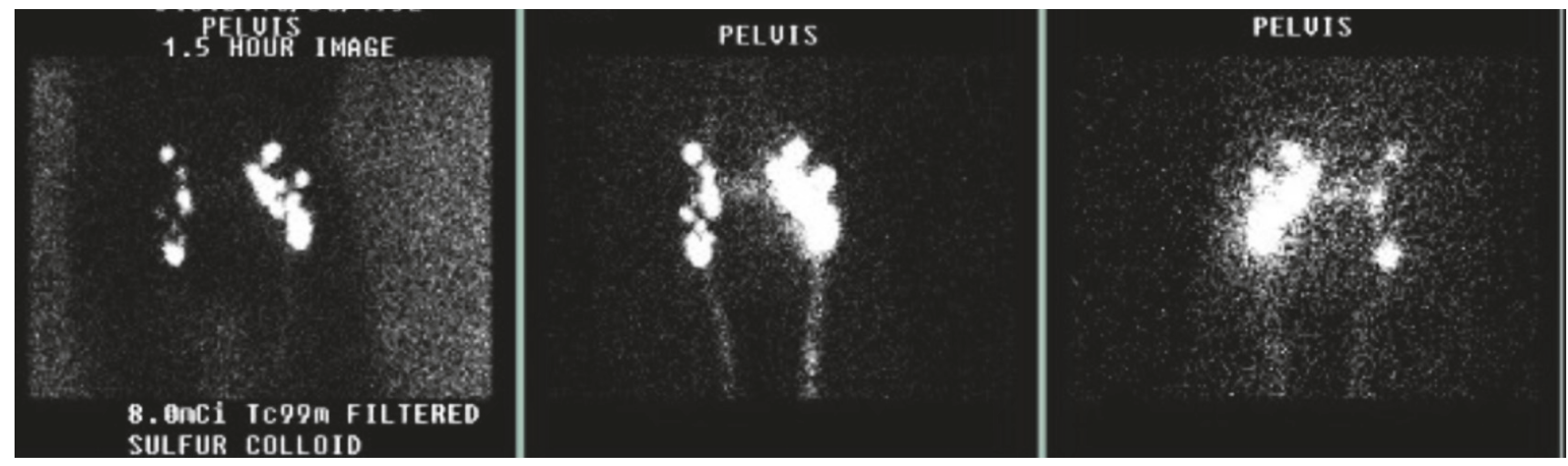

FIGURE 3: Lymphocytic scintigraphy results of the pelvic area showing no activity beyond the pelvis.

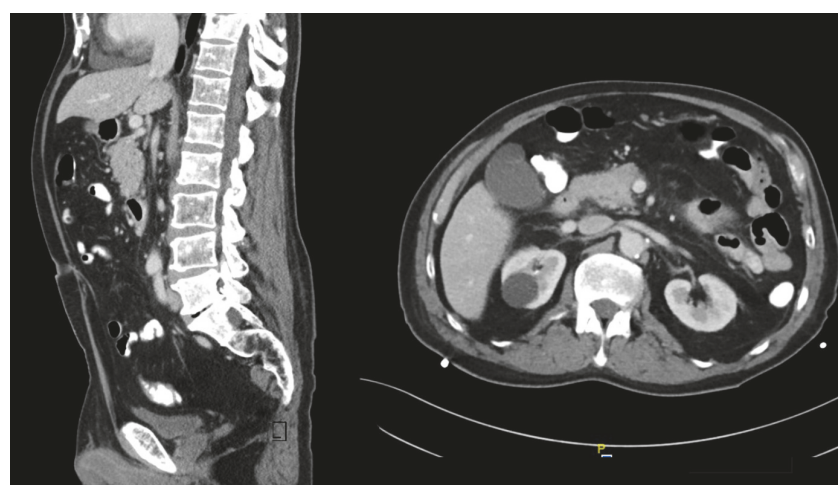

FIgURE 4: CT chest and abdomen/pelvis with contrast. Diffuse heterogeneous marrow signal of the thoracic spine and lumbar spine (left). Right kidney has several cysts with the largest measuring $2.8 \mathrm{x}$ $2.9 \mathrm{~cm}$ (right). Findings were suggestive of diffuse osteopenia versus bony metastasis.
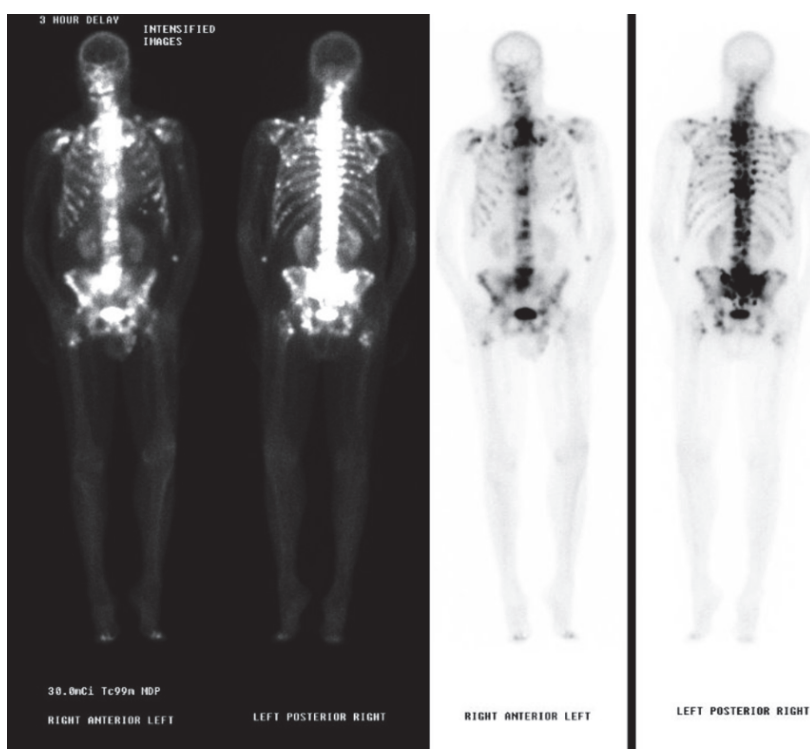

FIgURE 5: Whole-body bone scan showing multiple bony metastatic lesions throughout the skeleton.

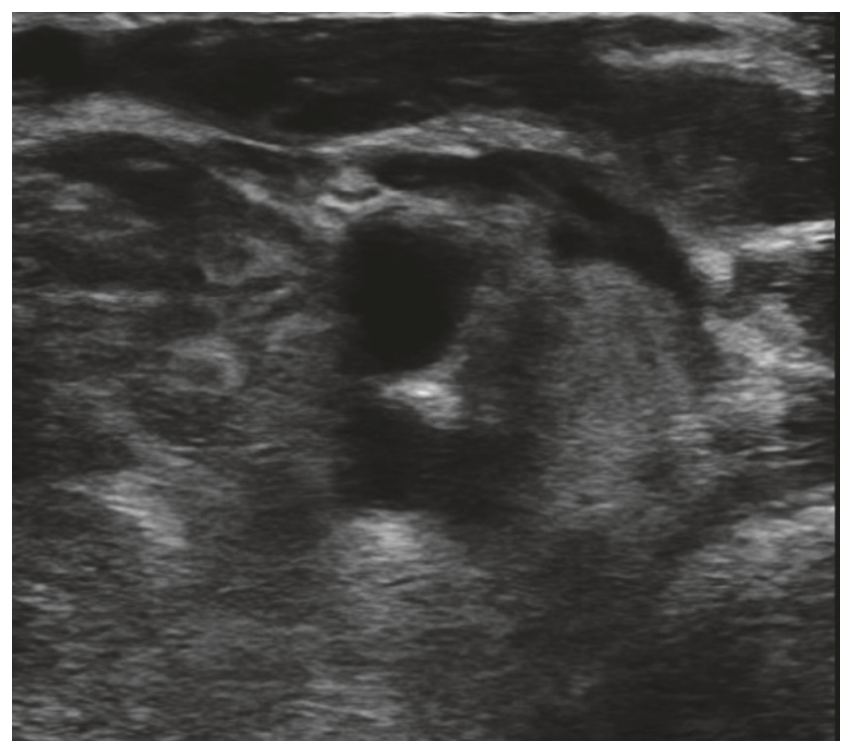

Figure 6: Venous ultrasound with Doppler of left upper extremity showing findings suggestive of a nonocclusive DVT of proximal/mid left subclavian vein which is difficult to compress.

of the time, with the final termination site varying between the left subclavian vein and internal jugular vein junction, the internal jugular vein, the external jugular vein, and subclavian vein [19].

In patients with chylothorax, once traumatic injuries have been ruled out, malignancy should be explored. If the initial CT fails to determine the cause, lymphatic imaging should be considered. Lymphoscintigraphy has shown good diagnostic utility in visualizing abnormal lymphatic flow in several case reports [20-22].

Management of chylothorax is dependent on the etiology and rate of accumulation of chyle. Initial measures include placement of chest tubes with medication adjuncts such as octreotide and somatostatin (to minimize lymphatic fluid excretion, increase splanchnic arteriolar resistance, and decrease GI flow which decreases lymphatic flow).

Surgical treatment can be done when conservative management fails. The most common surgical treatment is 


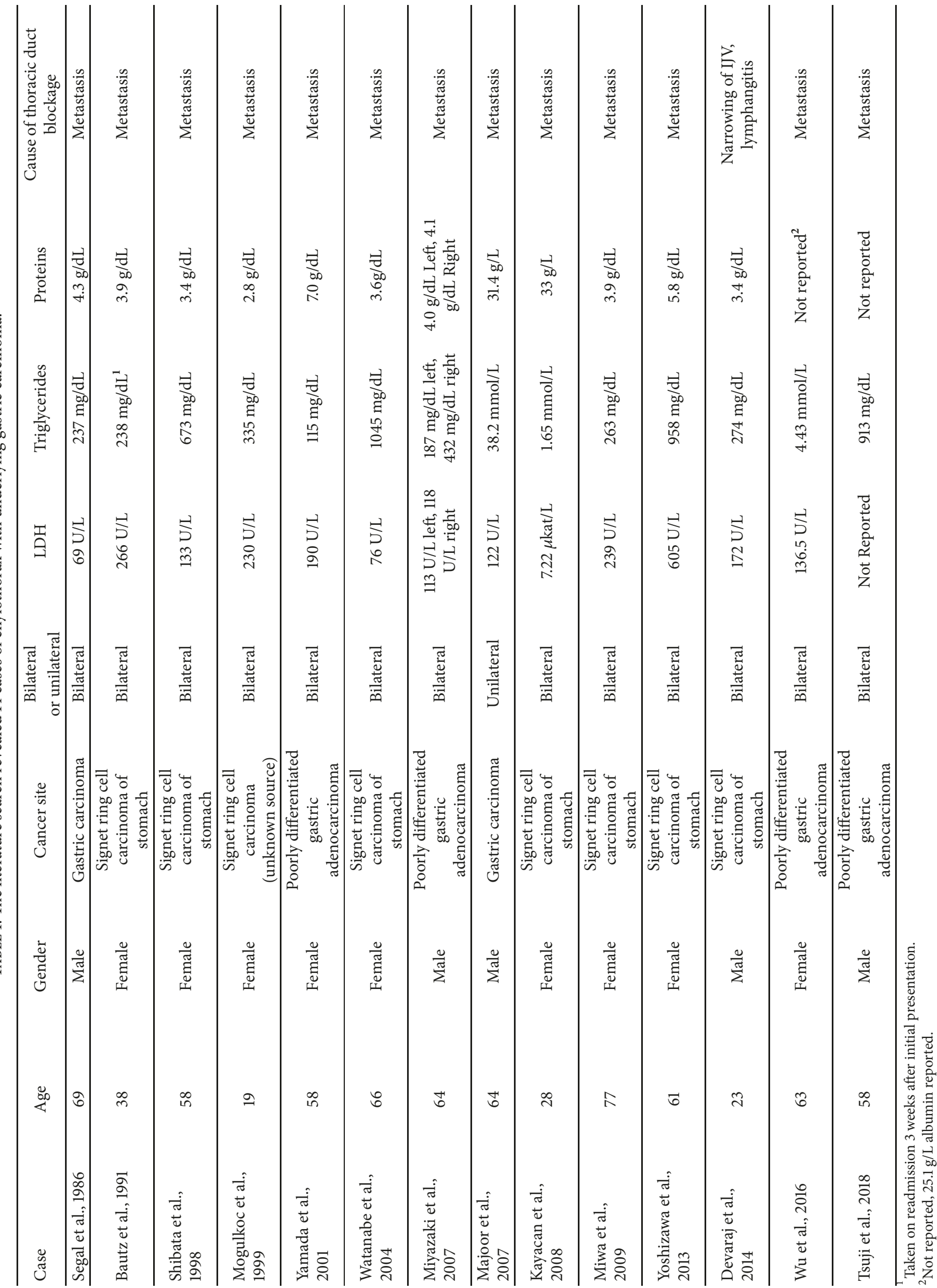


thoracic duct ligation but the mortality and complication rates can be as high as $25 \%$ and $38.3 \%$, respectively [23, 24].

Video-Assisted Thoracoscopic Surgery (VATS) has also increased in popularity for treatment. Nonsurgical causes of chylothorax rarely result in surgical intervention [25]. In our case, the patient's chylothorax resolved once interventional radiology performed thrombolysis of the left subclavian vein with balloon angioplasty. The uniqueness of this case comes from the diagnostic challenge and the approach, beside paucity of the reported cases in literature, as we found only 14 cases of chylothorax with underlying gastric carcinoma shown in the summarized table (Table 1) [9, 26-38]. Our case is unique among gastric malignancy-associated chylothorax in that a malignancy-related DVT caused the chylothorax. Other cases of gastric chylothorax were due to metastasis around the thoracic duct or lymphangitis leading to left internal jugular vein narrowing.

A higher suspicion of a malignant cause of the chylothorax can provide prompt diagnosis and shorten the length of stay. Repeat thoracentesis for pleural fluid analysis is encouraged whenever resolution of effusion is slow with conservative management.

\section{Conflicts of Interest}

The authors declare that they have no conflicts of interest.

\section{References}

[1] R. W. Light, "Pleural effusion," The New England Journal of Medicine, vol. 346, no. 25, pp. 1971-1977, 2002.

[2] V. Skouras and I. Kalomenidis, "Chylothorax: diagnostic approach," Current Opinion in Pulmonary Medicine, vol. 16, no. 4, pp. 387-393, 2010.

[3] F. Maldonado, F. J. Hawkins, C. E. Daniels, C. H. Doerr, P. A. Decker, and J. H. Ryu, "Pleural fluid characteristics of chylothorax," Mayo Clinic Proceedings, vol. 84, no. 2, pp. 129133, 2009.

[4] P. R. Jarman, M. K. Whyte, I. Sabroe, and J. M. Hughes, "Sarcoidosis presenting with chylothorax," Thorax, vol. 50, no. 12, pp. 1324-1325, 1995.

[5] G. Hillerdal, "Chylothorax and pseudochylothorax," European Respiratory Journal, vol. 10, no. 5, pp. 1157-1162, 1997.

[6] M. A. Judson and B. Postic, "Chylothorax in a patient with AIDS and kaposi's sarcoma," Southern Medical Journal, vol. 83, no. 3, pp. 322-324, 1990.

[7] C. H. Doerr, M. S. Allen, F. C. Nichols, and J. H. Ryu, "Etiology of chylothorax in 203 patients," Mayo Clinic Proceedings, vol. 80, no. 7, pp. 867-870, 2005.

[8] C. Cigarral, Á. Montero, C. Salas, G. Rodríguez, and A. de la Torre, "Chylothorax due to metastatic prostate carcinoma: an unusual complication," Clinical and Translational Oncology, vol. 11, no. 11, pp. 767-769, 2009.

[9] U. Devaraj, P. Ramachandran, M. Correa, and G. D/souza, "Chylothorax in gastric adenocarcinoma: A case report and systematic review of the English literature," Lung India, vol. 31, no. 1, pp. 47-52, 2014.

[10] L. A. Benninger, J. A. Ross, M. E. Leon, and R. Reddy, "An unusual case of chylothorax," Respiratory Medicine Case Reports, vol. 25, pp. 318-322, 2018.
[11] J. Pospiskova, L. Smolej, D. Belada et al., "Experiences in the treatment of refractory chylothorax associated with lymphoproliferative disorders," Orphanet Journal of Rare Diseases, vol. 14, no. 1, p. 9, 2019.

[12] S. Podder, M. Mora, V. Patel, and S. Sivamurthy, "A rare case of bilateral chylothorax: A diagnostic challenge-follicular lymphoma versus Primary effusion lymphoma," BMJ Case Reports, vol. 2015, Article ID bcr2015211935, 2015.

[13] S. Sonobe, K. Tachibana, N. Oomachi, S. Shimizu, M. Kitaichi, and S. Atagi, "Chylothorax in a 97-year-old woman with diffuse large B-cell lymphoma," Japanese Journal of Chest Diseases, vol. 73, no. 6, pp. 721-726, 2014.

[14] H. Tanrıverdi, F. Uygur, O. K. Tilkan, M. Gökçe, and M. Tor, "Chylothorax due to leukemic infiltration in a patient with chronic lymphocytic leukemia," Respiratory Medicine Case Reports, vol. 16, pp. 131-133, 2015.

[15] S. Hanina, C. Vivekananthan, R. Randhawa, M. Bhattacharya, P. Thomas, and A. Kavidasan, "Spontaneous chylothorax complicating small cell lung cancer - Review of aetiology and diagnosis," Respiratory Medicine Case Reports, vol. 15, pp. 51-53, 2015.

[16] C. H. Doerr, B. A. Staats, and S. N. Markovic, "Chylothorax in chronic lymphocytic leukemia patient," American Journal of Hematology, vol. 70, no. 3, pp. 237-240, 2002.

[17] C. Teng, K. Li, J. Yu, S. Hsu, R. Wang, and W. Hwang, "Malignancy-associated chylothorax: a 20-year study of 18 patients from a single institution," European Journal of Cancer Care, vol. 21, no. 5, pp. 599-605, 2012.

[18] S. S. Kho, S. T. Tie, S. K. Chan, M. C. Yong, S. L. Chai, and P. J. Voon, "Chylothorax and central vein thrombosis, an underrecognized association: A case series," Respirology Case Reports, vol. 5, no. 3, Article ID e00221, 2017.

[19] H. Hematti and R. J. Mehran, "Anatomy of the thoracic duct," Thoracic Surgery Clinics, vol. 21, no. 2, pp. 229-238, 2011.

[20] S. Ogi, N. Fukumitsu, M. Uchiyama, and Y. Mori, "A case of chylothorax diagnosed by lymphoscintigraphy using Tc-99m HSA-DTPA," Clinical Nuclear Medicine, vol. 27, no. 6, pp. 455456, 2002.

[21] K. Suga, N. Kume, A. Hara et al., "Abnormal lymphatic flow demonstrated by lymphoscintigraphy in chylothorax correlation with lymphography," Clinical Nuclear Medicine, vol. 24, no. 9, pp. 716-717, 1999.

[22] J. M. Restrepo and V. J. Caride, "Lymphoscintigraphy and radionuclide venography in chylothorax," Clinical Nuclear Medicine, vol. 29, no. 7, pp. 440-441, 2004.

[23] H. H. Schild, C. P. Strassburg, A. Welz, and J. Kalff, "Treatment options in patients with chylothorax," Deutsches Ärzteblatt International, vol. 110, no. 48, pp. 819-826, 2013.

[24] S. Paul, N. Altorki, J. Port, B. Stiles, and P. Lee, "Surgical management of chylothorax," The Thoracic and Cardiovascular Surgeon, vol. 57, no. 04, pp. 226-228, 2009.

[25] H. Zabeck, T. Muley, H. Dienemann, and H. Hoffmann, "Management of chylothorax in adults: when is surgery indicated?" The Thoracic and Cardiovascular Surgeon, vol. 59, no. 04, pp. 243-246, 2011.

[26] H. Tsuji, S. Hara, J. Urano, T. Samukawa, T. Makio, Y. Sugiyama et al., "Good controlled chylothorax in gastric carcinoma," Cancer \& Chemotherapy, vol. 45, no. 10, p. 1449, 2018.

[27] R. Segal, M. Waron, R. Reif, and E. Zecler, "Chylous ascites and chylothorax as presenting manifestations of stomach carcinoma," Israel Journal of Medical Sciences, vol. 22, no. 12, pp. 897-899, 1986. 
[28] J. B. Bautz, M. D. Delaney, R. Mostaghim, and R. F. Lodato, "Chylothorax as presenting manifestation of adenocarcinoma with probable gastric primary," CHEST, vol. 99, no. 4, pp. 1044$1045,1991$.

[29] K. Shibata, S. Kitagawa, M. Fujimura, and T. Matsuda, "Chylothorax associated with inflammatory carcinoma," Internal Medicine, vol. 37, no. 6, pp. 538-541, 1998.

[30] N. Mogulkoc, B. Önal, N. Okyay, Ö. Günel, and Ü. Bayindir, "Chylothorax, chylopericardium and lymphoedema - The presenting features of signet-ring cell carcinoma," European Respiratory Journal, vol. 13, no. 6, pp. 1489-1491, 1999.

[31] M. Yamada, S. Kudoh, K. Hirata, and J. Yoshikawa, "Bilateral chylothorax as initial manifestation of gastric cancer," The Journal of The Japanese Respiratory Society, vol. 39, no. 5, pp. 343-346, 2001.

[32] K. Watanabe, K. Yamauchi, K. Kobayashi, and H. Takeda, "A case of gastric cancer initially presented by bilateral chylothorax," The Journal of The Japanese Respiratory Society, vol. 42, no. 5, pp. 415-418, 2004.

[33] S. Miyazaki, H. Noda, T. Morita et al., "A case of gastric cancer detected incidentally following to chylothorax, followed by change in the appearance of pleural effusion with cancer progression," Japanese Journal of Gastroenterology, vol. 104, no. 9, pp. 1359-1364, 2007.

[34] C. Majoor, R. Aliredjo, P. Dekhuijzen, J. Bulten, and H. van der Heijden, "A rare cause of chylothorax and lymph edema," Journal of Thoracic Oncology, vol. 2, no. 3, pp. 247-248, 2007.

[35] O. Kayacan, D. Karnak, B. Ayşe Can, S. Dizbay Sak, and S. Beder, "Gastric signet-ring cell adenocarcinoma presenting with left arm deep-vein thrombosis and bilateral chylothorax," Clinical and Applied Thrombosis/Hemostasis, vol. 14, no. 4, pp. 476-480, 2007.

[36] M. Miwa, N. Kasamatsu, M. Shibata et al., "A case of gastric cancer with bilateral chylothorax," The Journal of The Japanese Respiratory Society, vol. 47, no. 12, pp. 1115-1119, 2009.

[37] K. Yoshizawa, Y. Sasaki, Y. Abe, N. Kanno, N. Mizumoto, M. Yagi et al., "Chylothorax in a patient with advanced gastric cancer and mediastinal lymph node metastasis causing thoracic duct obstruction," The Japanese Journal of Gastro-Enterology, vol. 110, no. 11, p. 1943, 2013.

[38] J. Wu, L. Lv, K. Zhou, and J. Huo, "Chylothorax and lymphedema as the initial manifestations of gastric carcinoma: a case report and review of the literature," Oncology Letters, vol. 11, no. 4, pp. 2835-2838, 2016. 


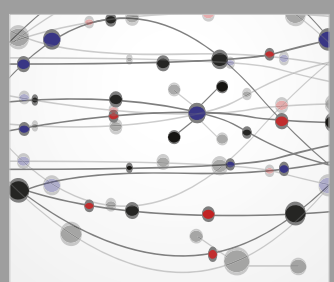

The Scientific World Journal
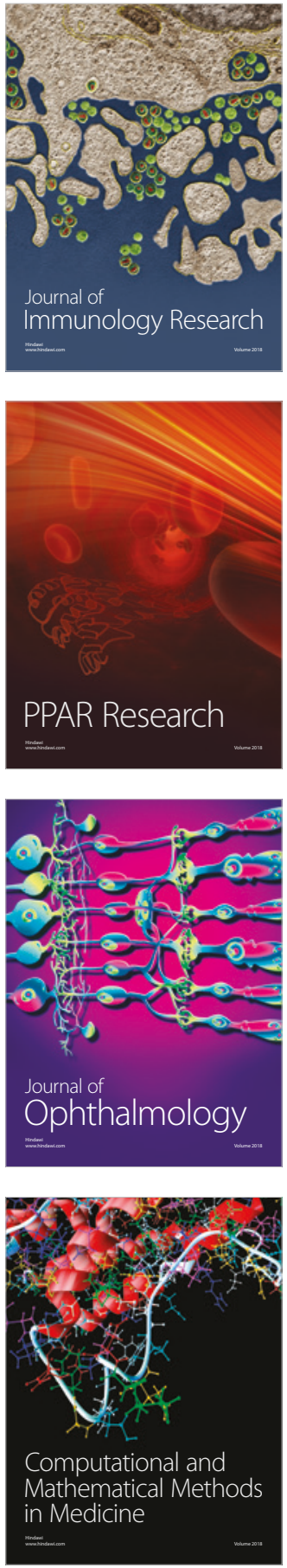

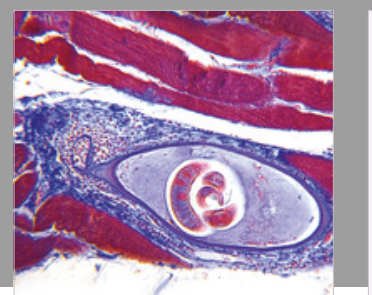

Gastroenterology Research and Practice

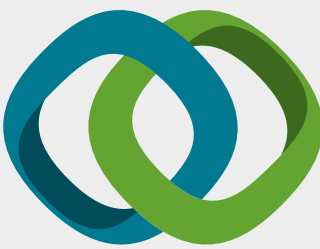

\section{Hindawi}

Submit your manuscripts at

www.hindawi.com
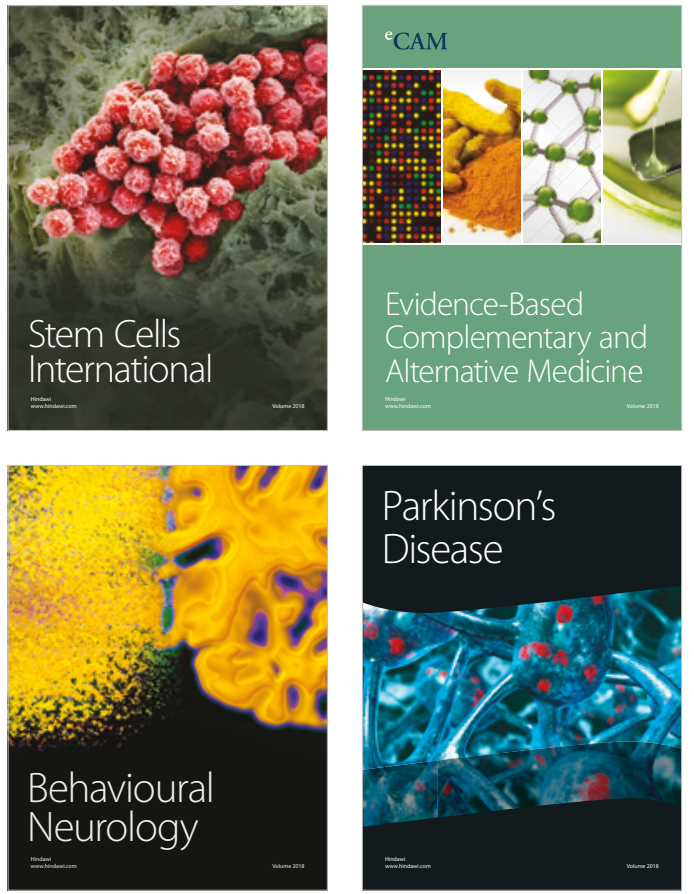

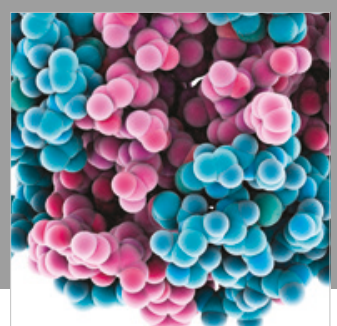

ournal of

Diabetes Research

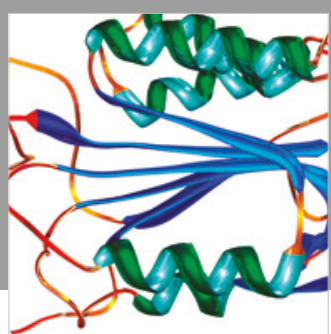

Disease Markers
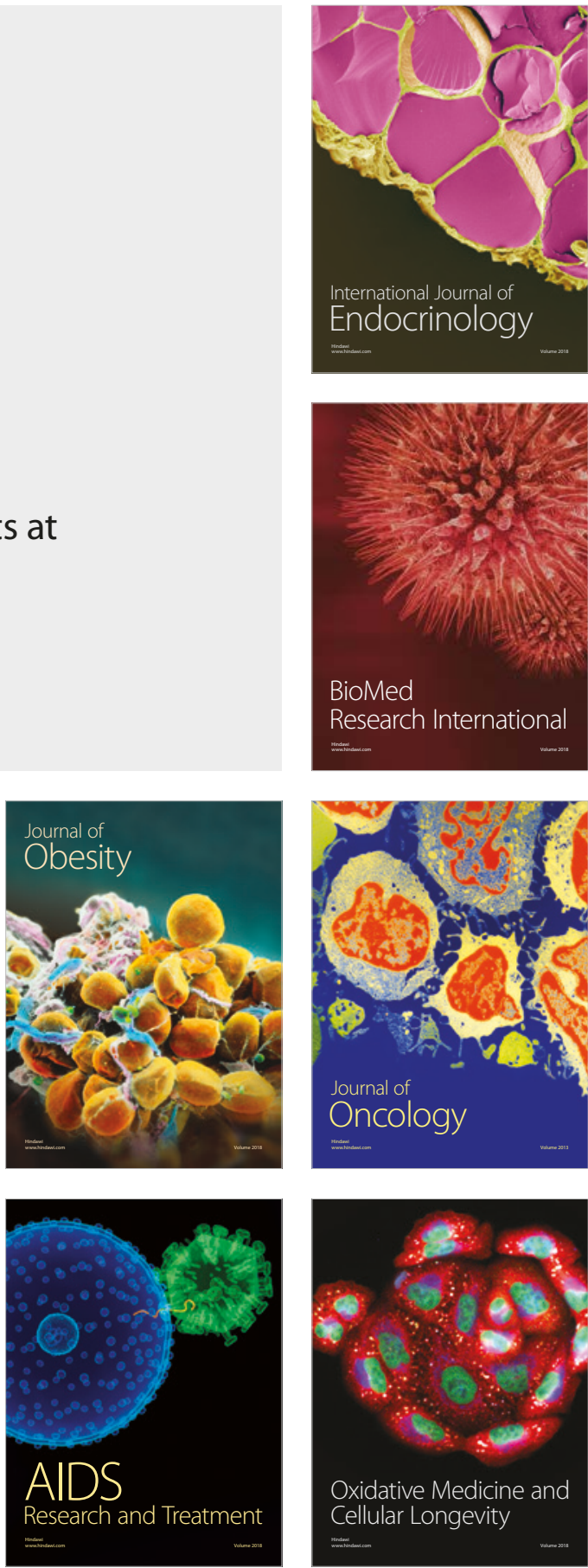